\title{
Nuevas derechas, viejas izquierdas
}

\author{
Una conversación con Enzo Traverso
}

\author{
Por Eugenia Sik y Ana Trucco Dalmas*
}

El pasado 12 de noviembre, Enzo Traverso arribó a la Ciudad de Buenos Aires. A dos años de su última visita a nuestro país, el historiador italiano — doctorado en París y, actualmente, profesor e investigador en Estados Unidos- dictó un seminario, dio conferencias, ofreció entrevistas a diferentes diarios nacionales y participó de conversatorios en nuestras universidades.

Las actividades, realizadas en el marco del Encuentro Internacional Marx 200 años, contaron con la presencia de un cuantioso e interesado público. ${ }^{1} Y$ esto es así porque la obra de Traverso constituye una referencia historiográfica de gran valor y de intensa recepción. Ciertamente, no es la primera vez que Traverso visita la Argentina. En el año 2001 fue invitado por la Universidad Nacional de La Plata (UNLP). En esta oportunidad se contactó con el director del $\mathrm{CeDlnCl}$, con quien contraería una relación intelectual y académica sostenida. ${ }^{2}$ En el año 2010, la universidad platense volvió a invitarlo. Tres años más tarde, Eduardo Jozami, en calidad de director del Centro Cultural de la Memoria "Haroldo Conti", invitó a Traverso a dictar seminarios y charlas. En aquella oportunidad ofreció una conferencia en el CeDInCl y visitó nuevamente la UNLP. En el año 2016, el Centro de Estudios de Memoria e Historia del Tiempo Presente (Universidad Nacional de Tres de Febrero), lo invitó a dictar un seminario sobre cine, historia y memoria. Finalmente, en el año 2018 y por invitación de Horacio Tarcus, Enzo Traverso fue partícipe central del Encuentro Internacional Marx 200 años, antes referido, convirtiéndose en la figura más convocante del evento.

Pero la presencia de Traverso en Argentina no se debe, tan sólo, a sus frecuentes visitas. Una parte importante de su obra ha sido traducida al español y publicada por editoriales argentinas que fueron pioneras en esta tarea, secundadas por editoriales españolas y mexicanas. ${ }^{3}$ Sus libros sobre historia europea contemporánea

* Eugenia Sik. CeDInCl-UNSAM; Ana Trucco Dalmas. CeDInCI-UNSAM-CONICET.

1 El encuentro se realizó en la Ciudad de Buenos Aires, durante todo el mes de noviembre y contó con la participación de Michael Heinrich, Razmig Keucheyan, Horacio Tarcus, Miguel Candioti, Ariel Petruccelli y Enrique de la Garza. Fue organizado por el Centro de Documentación e Investigación de la Cultura de Izquierdas (CeDInCl), el programa Lectura Mundi de la Universidad Nacional de San Martín (UNSAM) y la Fundación Rosa Luxemburgo. El programa del evento puede consultarse en el siguiente link: http://noticias.unsam.edu.ar/2018/11/18/encuentrointernacional-marx-200-anos/.

2 En la actualidad, Traverso forma parte del Comité Académico Internacional del anuario del CeDInCl, Políticas de la Memoria.

3 La primera traducción al español del primer libro de Enzo Traverso, Les marxistes et la question juive. Histoire d'un débat 1843-1943 (Paris, PEC-La Brèche, 1990), la hizo Agustín del Moral Tejeda para una editorial argentina, Ediciones del Valle. Este libro, titulado Los marxistas y la cuestión judía. Historia de un debate, fue publicado por primera vez en 1996 y reeditado en el año 2003 por la editorial AL Margen. EUDEBA, otra editorial argentina, publicó la traducción que Maximiliano Gurián hiciera de El totalitarisme: història d'un debat (Paris, Seuil, 2001). En el año 2003, Beatriz Horrac y Martín Dupaus tradujeron para Fondo de Cultura Económica (Argentina) La violence nazie. Une généalogie européenne (Paris, La Fabrique, 2002). Hacia el año 2009, la editorial argentina Prometeo publicó la traducción que encomendó a Miguel Ángel Petreca del libro A feu et à sang. De la guerre civile européenne 1914-1945 (Paris, Éditions Stock, 2007 ; rééd. sous le titre $1914-1945$. La guerre civile européenne, Paris, Hachette-Pluriel, 2009). Dos años más tarde, en 2011, también Prometeo, publicó la traducción de otro Libro de Traverso: Le passé, modes d'emploi. Histoire, mémoire, politique (Paris, La Fabrique, 2005); realizada por Lucía Vogelfang. Este último libro, titulado en español El pasado, instrucciones de uso: historia, memoria, política, tuvo una circulación considerable, y posee dos ediciones (la del 2011 y otra, en 2012). En 2012, Laura Fólica preparó la traducción de L'histoire comme champ de bataille. Interpréter les violences du XXe siècle (Paris, La Découverte, 2010), para Fondo de Cultura Económica (Argentina). Este último libro resultó ser un éxito editorial. En 2014, la editorial Siglo XXI publicó en Argentina la traducción hecha por María de la Paz Georgiadis de Conversation avec Régis Meyran, Où sont passés les intellectuels? (Paris, Textuel, 20,13); y, en el 2018, Horacio Pons tradujo para Siglo XXI Conversation avec Régis Meyran, Les nouveaux visages du fascisme (Paris, Textuel, 2017). Finalmente, en el año 2014, Fondo de Cultura Económica publicó en la Argentina la traducción de La fin de la modernité juive Histoire d'un tournant conservateur (Paris, La Découverte, 2013); y en el año 2018 publicó — también en Argentina — la traducción del último libro de Traverso encargada a Horacio Pons: Mélancolie de gauche: La force 
son consultados por investigadores, docentes y estudiantes de todo el país. Sus reflexiones historiográficas - libros como La historia como campo de batalla y El pasado, instrucciones de uso: historia, memoria, política-, constituyen un insumo fundamental de debate entre historiadores argentinos. Por su parte, sus estudios sobre memoria e historia han despertado un singular interés entre distintos humanistas y cientistas sociales. De más está decir que su público lector sobrepasa los límites académicos: la obra de Traverso ha sido discutida en círculos militantes, entre periodistas y autodidactas. La prensa argentina de alcance nacional (medios como Infobae, La Nación, Página/12, Clarín, Revista Ñ y Anfibia), se ha interesado por su obra y, de este modo, la ha difundido. A principios del año 2018, la editorial Siglo XXI publicó Las nuevas caras de la derecha, un libro que tuvo una tirada y una circulación significativas. Por otro lado, en los últimos meses del año 2018, Fondo de Cultura Económica publicó la traducción del último libro de Traverso: Melancolía de izquierda. Marxismo, historia y memoria; libro que fue presentado por el propio autor el pasado 16 de noviembre, en la Casa de la Lectura, ante un auditorio abarrotado.

La gravitación de su obra en el ámbito de la cultura y de la política argentina es, hace más de una década, un hecho indiscutido que representa algo más que el triunfo editorial de cierta bibliografía historiográfica de interés. Aunque - sin duda alguna - sus trabajos se inscriben dentro de una historia intelectual, la historia política, la historia de los intelectuales, podríamos afirmar con certeza que la preocupación por las derivas históricas de nuestro presente es una constante en la perspectiva de Traverso. No se trata de un historiador que ofrezca opiniones intuitivas sobre la actualidad política, autorizando su parecer en su condición de intelectual. Se trata, más bien, de preocupaciones genuinas, reflexionadas, detenidas. Libros como ¿Qué fue de los intelectuales? y Las nuevas caras de la derecha, atestiguan esta constante preocupación por la actualidad sociopolítica mundial. Es éste, tal vez, uno de los rasgos más singulares del gesto historiográfico que nos propone Traverso: un historiador que piensa su propio tiempo; singularidad que — posiblemente - sea un dato insoslayable para comprender el interés que ha suscitado su obra.

Así las cosas, en su última visita a la Argentina, tuvimos la oportunidad de conversar con Enzo Traverso. Pactamos una entrevista para debatir sobre la actualidad política latinoamericana, conmocionada ante la victoria de Jair Bolsonaro como presidente de Brasil. Su libro sobre las nuevas derechas, centrado en el caso francés y norteamericano, nos llevó a interpelarlo por otros escenarios. Con su lenguaje sobrio y modesto, sostenido en un español que maneja casi a la perfección, fue capaz de ofrecernos respuestas y observaciones contundentes y reveladoras; reflexiones que articula con una claridad inesperada.

A Enzo Traverso le propusimos conversar sobre el auge de nuevas derechas en Latinoamérica y sobre el fracaso de los gobiernos progresistas a nivel continental. Con cautela de especialista, nos ofreció su opinión sobre los movimientos feministas; conversamos sobre la situación de España y de México y su aparente excepcionalidad ante las tendencias geo-políticas globales. Nuestro encuentro llegó a su fin con un debate sobre la naturaleza del neoliberalismo y su penetración social ampliada. Y, de este modo, una tarde calurosa de noviembre, en un viejo hotel ubicado en San Telmo, conversamos con Enzo Traverso sobre nuestra contemporaneidad histórica.

d'une tradition cachée (XIXe-XXle siècle) (Paris, La Découverte, 2016). Este último libro, titulado en español como Melancolía de izquierda. Marxismo, historia, memoria, fue presentado por Horacio Tarcus en la actividad Esperando a Enzo Traverso, donde detalló los datos aquí consignados. La actividad se realizó en el marco del Encuentro Internacional Marx 200 años, y tuvo lugar el día 9/11/2018, en la Escuela de Humanidades de la Universidad Nacional de San Martín. 


\title{
Una conversación con Enzo Traverso
}

\begin{abstract}
- Recientemente se ha publicado en la Argentina la traducción de su libro Las nuevas caras de la derecha. En este libro usted caracteriza y define la especificidad de los nuevos imaginarios políticos del siglo XXI en función del surgimiento de una nueva derecha en Europa y Estados Unidos; fenómenos que ha conceptualizado bajo la noción de posfascismo. Como usted mismo indicó en el prefacio a la reciente edición castellana de Las nuevas caras de la derecha, se podrían establecer ciertos tipos de comparaciones o paralelismos entre los fenómenos europeos o norteamericanos y los devenires políticos latinoamericanos, en lo que respecta al renacer de las derechas y su consolidación como vía de posibilidad institucional. Tomando como punto de partida su diagnóstico sobre la actualidad histórica y los imaginarios políticos del siglo XXI inspirados en tradiciones de 'derecha', quisiéramos hacerle una serie de preguntas sobre la realidad latinoamericana. ¿Cree usted posible utilizar la noción de posfascismo para analizar algunas expresiones políticas latinoamericanas? ¿Considera que en este lado del continente americano comienzan a surgir conglomerados políticos de matriz fascista pero reformulados a partir de otros insumos, corrientes y tradiciones?
\end{abstract}

- El fascismo tiene su propia historia en Latinoamérica, especialmente en la Argentina. Pero si en Europa la referencia al fascismo clásico es el período de entreguerras, en Latinoamérica la referencia al fascismo clásico son las dictaduras militares de la década del '70, entre los años '60 y los ' 80 . Hay algunas particularidades que hay que tomar en cuenta. Sin embargo, la noción de posfascismo me parece pertinente porque el posfascismo es un fenómeno nuevo, es decir, es una derecha radical, una derecha extrema, que presenta rasgos nuevos que la distinguen del fascismo clásico y, en muchos casos, los líderes de esos movimientos no se definen fascistas y subrayan todas las diferencias que lo separan del fascismo clásico. Y esa es una de las razones que explican su éxito, porque los movimientos neofascistas, que simplemente reivindican una continuidad con el fascismo de los años '30 o el nazismo — que existen en Europa Central o en Grecia—, no son movimientos que tengan la misión de ganar elecciones y tomar el poder político, son marginales.

Entonces, posfascismo porque se diferencia del fascismo clásico, pero, al mismo tiempo, el fascismo es —-todavía— la matriz de muchos de esos movimientos; y porque para todos los observadores es imposible definir esos movimientos, esas corrientes, sin tomar como referencia el fascismo clásico. Son entidades transitorias entre el fascismo clásico, que no está más vigente, y otra cosa que no está muy bien definida.

Son movimientos que pueden evolucionar hacia una forma de conservadurismo liberal (una derecha autoritaria en el marco de la democracia liberal), o pueden regresar al fascismo clásico. Por ejemplo, en el supuesto caso de una crisis económica global, de una descomposición del sistema político, estos movimientos podrían volver a una forma más clásica de fascismo. Hoy, todas las evoluciones son posibles.

En el caso de Jair Bolsonaro, por ejemplo, es posfascismo porque Bolsonaro no es el líder de un movimiento fascista. Es decir, Bolsonaro no es alguien que desde hace tiempo dirige un movimiento fascista y que ahora ganó las elecciones. A Bolsonaro lo pienso como a Donald Trump en Estados Unidos, hay todo un debate sobre la relación entre Trump y el fascismo. Pero Trump no tiene ninguna idea de lo que fue el fascismo, no lo conoce y, yo creo, tampoco Bolsonaro. Es decir, son personalidades fascistas, hablando con las categorías de Theodor W. Adorno y de la Escuela de Frankfurt. Personalidades que tienen el nivel máximo de autoritarismo y que lo acercan al fascismo, pero que no tienen referencias ideológicas fascistas, que no tienen una cultura fascista, que no son los líderes de movimientos fascistas organizados, como fue el caso de Benito Mussolini en Italia, de Adolf Hitler en Alemania, o de muchos otros movimientos fascistas de los años de entreguerras. Tampoco tienen las referencias ideológicas que tuvieron los fascismos latinoamericanos, brasileños o argentinos en el pasado, que fueron una mezcla de fascismo europeo, de nacional-catolicismo, de antisemitismo, de nacionalismo radical... bueno, son otra cosa. 
- ¿Existe un posible parangón entre el fenómeno Bolsonaro, Trump en EEUU y el fortalecimiento de las derechas radicales en Austria, Alemania y Francia? A propósito de Bolsonaro, ¿cómo podría comprenderse su triunfo? Es posible pensarlo en función del horizonte de transformación social construido por el Partido dos Trabalhadores (PT) y traicionado por la misma fuerza política? Esto es: ¿el PT habría tratado de crear un horizonte utópico que — con el correr de los años- fue traicionado?

- Conozco muy mal la situación brasileña, entonces, repito: no tengo ninguna autoridad para dibujar un análisis que pueda ser prescriptivo, pero yo estoy convencido de una cosa: la victoria de Bolsonaro no es un accidente. Hay una tendencia general, una tentación a explicarlo como una especie de evento inesperado, como la caída de un meteorito ¿no? Hace seis meses Bolsonaro era un tipo muy marginal del cual todo el mundo se reía y ahora ganó las elecciones. Hubo un error de cálculo del PT, porque ellos tenían la ilusión de presentar a Inázio Lula Da Silva y fueron incapaces de preparar una campaña electoral eficaz con un candidato ya legitimado. Bueno, sí, todos estos errores existieron, pero no es eso lo que explica la victoria de Bolsonaro. La victoria de Bolsonaro es una derrota del PT, no es un accidente, es la conclusión de un ciclo, y ese es el problema de fondo. Es la derrota de una estrategia que persiguió el PT durante años.

— En relación a esta derrota, ¿le parecería pertinente pensar en los "socialismos del siglo XXI" latinoamericanos como un intento de recrear utopías, horizontes utópicos o invenciones de futuros que auguraban transformaciones sociales? ¿O considera que la experiencia de los "socialismos del siglo XXI" fue producto de imposturas discursivas y de esa dualidad se alimentaron las derechas que los derrotaron?

- Yo no creo que el horizonte utópico fuera tan fuerte. El nacimiento del PT a principios de los años ochenta levantó muchas esperanzas, seguro; fue el fin de la dictadura militar, la aparición de una fuerza de izquierda, popular, con una base obrera. Levantó esperanzas extraordinarias en todas las capas populares, las clases subalternas ¡con un líder como Lula! Pero hablar de un horizonte utópico me parece un poco exagerado. En Latinoamérica hubo una desincronización política en relación a las tendencias políticas globales. Es decir: hubo una década en la cual la izquierda tenía una posición muy difícil. En Estados Unidos era inexistente, Europa estaba en una crisis profunda... fue una época dominada por el neoliberalismo. En este contexto, Latinoamérica era diferente: un continente en el cual la izquierda estaba activa e indicaba una pauta de resistencia. Entonces, yo hablaría más de una esperanza de resistencia posible que un horizonte utópico abierto. Hay una diferencia.

Hoy se produce una sincronización global, es decir: ese ciclo de izquierda latinoamericana más o menos se acabó, porque en todos los países la izquierda dejó el poder, perdió las elecciones o está en una crisis profunda como Venezuela —una crisis trágica-, o Bolivia, en donde se produjo una declinación de todas las esperanzas que levantó Evo Morales cuando fue elegido por primera vez. Hoy se produce una sincronización, la emergencia de este posfascismo latinoamericano se inscribe en una tendencia general y Bolsonaro fue sostenido por esa tendencia general. De hecho, la victoria electoral de Bolsonaro se produce después de la victoria de Donald Trump en Estados Unidos, y luego del crecimiento de la derecha radical en toda Europa y en la Unión Europea. Hoy se trata de una tendencia general.

Lo que falleció fue el proyecto de resistencia al neoliberalismo. Desde este punto de vista, lo que hoy ocurre en Brasil es emblemático de tendencias continentales. Es decir: en Brasil todo esto aparece de una manera mucho más evidente porque ¡es Brasil! una potencia en el mundo, un país que tiene un impacto continental y que es mucho más grande que el de Ecuador o el de Bolivia. Es la derrota de una estrategia, que no era un proyecto de alternativa al sistema, no se trataba de un horizonte utópico, o de la construcción de otra sociedad posible. La estrategia era una resistencia a la dominación neoliberal global, hecha de políticas de redistribución de la riqueza — permitida por márgenes de crecimiento de la economía en varios países - y que tenía como objetivo la inclusión de capas populares que estaban excluidas del sistema, que estaban afectadas profundamente por la pobreza. Pero eran políticas de redistribución de la riqueza que nunca ponían en cuestión el modelo económico dominante, y eso funcionó cuando Brasil tenía un porcentaje de crecimiento de 7\%, cuando existió la posibilidad de redistribuir, de incluir. Cuando ese margen se agotó esa política no marchó más. El PT no concibió una alternativa de sistema y contrajo compromisos con las capas más poderosas. El bloque social detrás de Lula estaba representado por las clases populares y por el capitalismo brasileño que se acomodó. Es esa estrategia la que fracasó. El resultado es que mucha gente que votó por el PT en el pasado, ahora vota por Bolsonaro. Porque con esa política de alianzas el PT se involucró, se integró al sistema sin ponerlo en cuestión, y las consecuencias son evidentes: al aceptar ese marco, después de años, el PT se convirtió en un partido del sistema, en un partido que no podía concebir su política sin coaliciones, sin alianzas, un partido que se volvió corrupto, porque esa es la realidad: hay corrupción en el PT que es la corrupción en un partido que maneja y gestiona el poder desde hace años. Y ahora se pagan las consecuencias de todo eso. 
Entonces, para luchar efectivamente en contra de Bolsonaro hay que cambiar de estrategia. Algo similar ocurrió en Venezuela, a pesar de todas las diferencias. Utilizaron el poder central para distribuir la riqueza sin poner en cuestión un modelo de subdesarrollo basado en una industria extractiva. Y fue la corrupción lo que al final gangrenó el poder.

\section{- Usted ha dicho que España es un laboratorio para las izquierdas europeas, y ha resaltado como fenómeno singular la ausencia en ese país de nuevas derechas o articulaciones políticas posfascistas. Aquí, en América Latina, el triunfo de Andrés Manuel López Obrador en México parece contradecir la ola conservadora que comienza a consolidarse a nivel continental. ¿Cómo evalúa la actualidad política de México y de España?}

- Bueno, no conozco muy bien la situación mexicana. López Obrador no es una figura nueva que levanta esperanzas porque encarne algo nuevo. López Obrador es un viejo político que, sin dudas, es muy respetable, pero su victoria no se compara, por ejemplo, al nacimiento del PT en 1980, es otra cosa ¿no? Es una victoria electoral que sigue otras tentativas que fracasaron, que sigue tentativas de construcción alternativas al Partido Revolucionario Institucional (PRI) que, en el pasado, levantaron esperanzas y que fracasaron en muchos casos. Entonces, al triunfo de López Obrador yo lo explico mucho más por el descrédito de Enrique Peña Nieto. No veo una ola de movilización social y política que lleva a López Obrador al poder. Después vamos a ver lo que hace, porque la situación de México es dramática, se confronta con problemas enormes que son externos e internos, es decir: una relación muy conflictiva con Estados Unidos y con Trump, y una situación interna con un nivel de violencia que es endémico y que gangrena la democracia de una manera muy profunda. Es decir: México tiene su contexto particular.

El caso de España es diferente porque, digamos, España sí es una excepción en Europa. En Europa la derecha radical está creciendo en todos los países y existe el riesgo de que gane las elecciones el año próximo y, en este caso, provocaría una crisis mucho más profunda que la del Brexit en la Unión Europea. Las repercusiones serían muy grandes, la situación europea es dramática. España es una excepción porque es el único país, gran país europeo, en el cual no hay una derecha radical. Creo que las razones son históricas, es decir, España es un país en el cual el Partido Popular (PP) tuvo (¡hay que reconocerlo!) esa gran capacidad de legitimarse como partido conservador en el marco de la democracia liberal, absorbiendo la herencia del franquismo. La derecha radical en España no tiene una representación o una forma política, porque se expresa dentro del PP y a veces aparece de una manera explícita.

Por ejemplo: durante la crisis catalana, las movilizaciones en contra de la independencia tenían un sabor neofranquista muy, muy evidente. Entonces, se trata de un nacionalismo que a veces se expresa en formas radicales, autoritarias. Personalmente no estoy a favor de la independencia de Cataluña, pero por supuesto que estoy a favor del principio de autodeterminación de los pueblos, y poner en la cárcel dirigentes políticos elegidos democráticamente me resulta una medida autoritaria que tiene un sabor neofranquista. En este contexto, el PP tiene la capacidad de impedir la aparición de una fuerza posfascista. Su problema no es la derecha sino la "izquierda", porque su competición es con Ciudadanos, que es una ruptura a la "izquierda" del PP y que se creó como respuesta a la corrupción del PP. Ciudadanos es una fuerza política conservadora pero liberal, más abiertamente neoliberal. No tiene los límites del PP que está muy vinculado a una cierta tradición, a valores muy tradicionales y conservadores que son la familia y la patria, ¿no?, Ciudadanos es un partido más moderno, más neoliberal en cierto sentido, más coherente, más claro. El problema del PP es Ciudadanos, que no es una sub-escisión a su derecha hoy.

\section{- En relación a la caracterización de estos escenarios internacionales ¿qué opina sobre la vinculación y comparación que muchos establecen entre la actualidad global y la década del ' 30 ?}

— La comparación es pertinente y hay muchos analistas y observadores que hacen esa comparación y no es por casualidad. Europa está viviendo una crisis muy profunda y, más allá de Europa, el mundo está viviendo una crisis profunda, el mundo global se encuentra sin un orden, sin perspectivas claras, nadie puede decir cómo será el futuro.

Salimos de un siglo en el cual había un orden, había un orden bipolar, todos los cambios y las alternativas estaban encerradas en un orden geopolítico del mundo. Este orden se derrumbó y, desde entonces, todo es posible: una descomposición de la Unión Europea puede producir un escenario imprevisto; una reelección de Trump, que no se puede desestimar, tendría consecuencias a largo plazo; un desarrollo de las derechas radicales en todo Latinoamérica después de una posible consolidación de Bolsonaro en Brasil... todos los escenarios están abiertos y también los peores. Pero, en realidad, la situación es muy diferente con los años '30 y la comparación revela más las diferencias que las analogías. 
- Como menciona en su libro Las nuevas caras de la derecha, el posfascismo tiene entre otras características, una matriz antifeminista, aunque también se apropian y subvierten algunos discursos por la igualdad de género. Por otro parte, tanto en el caso del ascenso de Trump como en la reciente asunción de Bolsonaro, han sido masivas las movilizaciones de mujeres en contra de ambos líderes ¿Qué opinión tiene acerca del horizonte radical de los movimientos feministas ante estas nuevas derechas?

— En este caso, tengo aún menor autoridad para contestar esa cuestión. Tendríamos que convocar a militantes feministas involucradas en esos movimientos. Yo quiero subrayar que, de una manera general, la misoginia, el antifeminismo y la homofobia son rasgos de todos los nacionalismos y, por supuesto, de los fascismos y también de los posfascismos. Adquieren formas diferentes según los diferentes contextos, a veces contradictorias. Que Trump y Bolsonaro sean antifeministas y homófobos, no hay ninguna duda sobre eso. Su comportamiento lo ilustra muy bien, y su retórica y sus declaraciones son muy claras al respecto.

En Europa la situación es mucho más contradictoria. Es decir, hay una derecha radical que gobierna Polonia y que quiere derogar la ley del aborto, por ejemplo. Hay centenas de miles de mujeres que se manifiestan en Varsovia para defender esa ley. $Y$ en otros países hay situaciones similares. En Europa Occidental, en Francia, por ejemplo, la derecha radical reivindica el feminismo como una herencia propia, como un conjunto de derechos que dice defender mejor que la izquierda afirmando, por ejemplo, que los derechos de las mujeres están amenazados por la inmigración islámica, y entonces hay que votar por la derecha, por el Front National (FN).

— ¿La radicalidad de estos movimientos dependería de los escenarios? Es decir ¿la posibilidad por parte de los feminismos de combatir a la derecha dependería de estos escenarios y configuraciones políticas nacionales?

- Sí, seguro, pero hay tendencias generales. En Francia los homófobos y los misóginos votan por el FN. Hace tres años hubo un gran movimiento en Francia, una verdadera ola reaccionaria que se llamó La Manif pour Tous [La Manifestación para Todos]. Era un movimiento en contra del matrimonio gay, en contra de una ley que no limitaba los derechos de los heterosexuales, o de las familias heterosexuales, sino que pedía igualdad de derechos para las parejas homosexuales. Fue un movimiento muy poderoso y muy reaccionario, en defensa de la familia, que sostenía que el lugar de la mujer está en el hogar y que las parejas homosexuales son una amenaza. Ese era el discurso. Por supuesto, este movimiento fue una de las condiciones para el éxito electoral del Front National en las elecciones presidenciales.

Pero Marine Le Pen tuvo la inteligencia de no identificarse con este movimiento. Ella dijo "sí, ellos se manifiestan, pero no es la posición del FN". El principal colaborador de Marine Le Pen, Sébastien Chenu, es un gay reconocido como tal. Y Marine Le Pen insiste en que su política se inscribe en un marco demócrata, republicano, que reconoce las conquistas del feminismo y que, precisamente para defenderlas, hay que excluir y rechazar a los inmigrantes.

Digamos, es un feminismo xenófobo: hay una forma de racismo feminista, en la retórica, en el discurso. $Y$ hay corrientes del feminismo nacional republicano que son muy cercanas a este planteo: Elisabeth Badinter, todas las declaraciones de sus últimos años van en ese sentido, Caroline Fourest es una de las islamófobas más radicales y son todas feministas. Es decir: el desarrollo, la influencia de la derecha radical evidenció todo un sistema de contradicciones propias de la historia del feminismo francés. Y podríamos hacer consideraciones análogas con otros países como Italia, Holanda, Bélgica, Dinamarca.

\section{— O sea que el feminismo le parece más susceptible de ser absorbido por las derechas...}

- No, yo digo simplemente que hay que tomar en cuenta esas contradicciones. La derecha radical francesa no es la derecha radical de Polonia. Hay muchas diferencias entre ellas. En la década de los '30 no se podía imaginar un movimiento fascista liderado por una mujer, era una contradicción. Hoy es algo posible y no plantea ningún problema. Marine Le Pen es una política muy capaz, muy inteligente, que tiene una cultura política, y es reconocida como tal. Y seguro hay en el cuerpo electoral del FN una generación de fascistas o de reaccionarios que hubiera preferido un hombre pero, de manera general, eso no genera problemas.

Entonces, hay un nuevo discurso de la derecha radical que es muy diferente en términos ideológicos con respecto al viejo discurso fascista. Por ejemplo, en Europa occidental —en Estados Unidos la situación es diferente_ el feminismo clásico 
fue incapaz de conectarse con la lucha por los derechos de los afroamericanos, que eran mucho más fuertes que en Francia o en otros países. El feminismo clásico no se conectó con el anticolonialismo, con las luchas por los derechos de los inmigrantes, una inmigración poscolonial. Por esa falta de conexiones, de diálogo o, para hablar con las categorías de hoy, de interseccionalidad entre esas corrientes, se paga un precio. $Y$ el precio es que hay un feminismo reaccionario, un feminismo casi neocolonialista, un feminismo xenófobo. $Y$ eso es algo nuevo.

No es la imagen del feminismo que históricamente se conoce. Y no digo que esa corriente represente a todo el feminismo de hoy, es decir, es una corriente. La cuestión del velo islámico rompió al feminismo en Francia. Hay mujeres que luchan por la autoorganización de las mujeres islámicas, por la defensa de sus derechos y por la defensa de los derechos de las mujeres en contra de todas las fuerzas reaccionarias que hay en el Islam y que, por supuesto, se expresan también en la sociedades europeas. Pero hay otras corrientes para las que el feminismo es una forma de laicismo, de secularización que es incompatible con el velo islámico. Entonces, la cuestión no es tan simple. La nueva derecha develó las contradicciones del feminismo más que enfrentarse radicalmente a éste y lo descompuso antes de que pudiera levantar una resistencia al posfascismo.

\section{— Pero en el caso de Estados Unidos o de Brasil, por ejemplo, esta emergencia de los posfascismos, al marcar estas contradicciones, como lo señala Nancy Fraser, ¿no le reimprime al feminismo este horizonte radical priorizando dentro del feminismo esta corriente?}

- Sí, pero la situación en Estados Unidos es muy diferente porque allí no hay un feminismo que tenga un discurso fuerte y tampoco Trump quiere lograr el apoyo de corrientes feministas. La relación entre Trump y el feminismo es una relación de enfrentamiento radical. En Francia no es así, esa es la diferencia.

Y Nancy Fraser tiene razón —desde mi punto de vista_ al decir que uno de los problemas del feminismo es que hay que conectarlo a la cuestión social. Esa es una de las lagunas de la tradición feminista que explica por qué hay mujeres que apoyan a Bolsonaro, que apoyan a Trump y con mucho entusiasmo. Si hubiese existido una conexión entre feminismo y condición social de las mujeres, probablemente hubiera sido más difícil para esas derechas lograr cierta influencia en algunas capas sociales. No sé si recuerdan, hace dos años, durante la campaña electoral, Hillary Clinton se presentaba como la candidata de las feministas, de los derechos de las mujeres. En cierto momento hizo declaraciones sobre los electores de Trump que fueron tan inapropiadas que hubo muchas feministas que tomaron distancia con respecto a Hillary Clinton. Apareció como la defensora de las mujeres cultas, urbanizadas y pertenecientes a capas superiores que desprecian mucho a las mujeres pobres que votan a la derecha. Ese era el discurso que ella articuló de una manera muy clara. Un feminismo concebido en el sentido de Nancy Fraser es un feminismo que critica esa postura. En Estados Unidos, Hillary Clinton tenía un discurso muy similar al de Elisabeth Badinter en Francia, o al de las feministas que, en Italia, apoyan al Partido Demócrata (Partito Democratico) en contra de la Liga Norte. El caso de Italia es diferente, pero hay una tendencia general.

- Usted ha afirmado que el posfascismo es aquella respuesta que surge ante la crisis de aquello que se consolidó al comenzar la década de los 90: la globalización neoliberal. Sin embargo, gran parte de las nuevas derechas posfascistas bien podrían ser hijas del programa político, social y económico de esa globalización neoliberal. Es más: ninguna de ellas podría renegar demasiado de ellas: la entronización del capitalismo financiero es una expresión de este vínculo. En América Latina, por ejemplo, el fracaso de la globalización neoliberal es un factor explicativo de eso que se mal llamó 'socialismo del siglo XXI' y las nuevas derechas latinoamericanas se presentan como la alternativa a esas expresiones anti-neoliberales, que vienen a restaurar ese neoliberalismo. En función de todo esto: ¿cuál es, para usted, la naturaleza del vínculo entre nuevas derechas posfascistas y la globalización neoliberal que emergió de la caída del muro de Berlín?

- Yo creo que no hay una relación mecánica, no hay una causalidad determinista. Bolsonaro es un neoliberal salvaje y es un fascista que reivindica una forma de neoliberalismo casi neodarwinista, es decir, la selección natural, los más fuertes que aplastan a los débiles.

En Europa, no hay ningún líder de un movimiento de derecha radical que defienda posiciones similares. En Europa, una de las premisas del crecimiento y del éxito electoral de esos movimientos es su postura en contra del neoliberalismo. El neoliberalismo se asocia a la Unión Europea, a las políticas de austeridad de la Unión Europea y a la proliferación normativa que impide a los gobiernos cualquier política social. Y eso explica la insistencia de esos movimientos sobre la "soberanía", el restablecimiento de las fronteras para, por un lado, impedir la invasión de los inmigrantes y, por el otro, fortalecer la 
posibilidad de ser "soberanos" en la elección de sus políticas. Entonces, una de las premisas del éxito de la derecha extrema europea es su oposición al neoliberalismo. Es una oposición al neoliberalismo que implica también políticas sociales, pero políticas sociales xenófobas.

Las derechas europeas afirman: "nosotros vamos a defender el Estado social, pero para los franceses, o para los italianos, no para los inmigrantes (y aún menos para los inmigrantes islámicos que amenazan nuestra identidad cultural, etc. etc.)". Ese es el discurso. En Italia, Matteo Salvini ha ganado las elecciones. Su discurso es xenófobo, es nacionalista, es racista, muy claramente. Pero su política social, por lo menos en términos de lo que ha prometido, es mucho más progresista o social que la política social y económica de los gobiernos de centro izquierda. Y eso explica el apoyo popular a esos gobiernos. Sin embargo, se trata de una política social xenófoba: "estamos para proteger los derechos de las jubilaciones", "estamos en contra de una reforma laboral que golpee los salarios", "estamos para defender una política sanitaria que sea aceptable, digna", "estamos para financiar la educación pública", pero en la forma más caricaturesca: en la escuela primaria los niños hijos de inmigrantes jno tienen derecho a comer en el restaurante! No es la política neoliberal que dice: "hay un restaurante, quien puede paga". Hay un restaurante, pero la política pública social es para los italianos, no para los inmigrantes. Esa es la lógica de la nueva derecha. Y ese es el caso de Europa. Bolsonaro es otra cosa. Y Trump también es otra cosa porque es una mezcla de neoliberalismo salvaje y de proteccionismo.

Entonces, el neoliberalismo no es una política económica. No es simplemente un conjunto de medidas económicas y sociales que se acomodan mejor a una forma política que a otra. En Estados Unidos la candidata de Wall Street era Hillary Clinton, no era Trump. En Estados Unidos el Partido Republicano — que es uno de los pilares del sistema político- hizo todo lo que pudo para impedir que Donald Trump sea su candidato. Y, seis meses después de la elección de Trump, había todo un conjunto de banqueros, de representantes de Wall Street dentro del equipo de Trump. El neoliberalismo se adapta a todos los gobiernos, en Europa a los gobiernos de centro izquierda, en Brasil se adaptó al gobierno de Lula y lo hará con el de Bolsonaro, porque el neoliberalismo no es un conjunto de políticas económicas.

Yo sostengo que el neoliberalismo es más que un modelo económico, es un modelo antropológico, es decir: es una forma de civilización y de sociedad que implica el establecimiento normativo del individualismo y de la competición. Por ello, el neoliberalismo sostiene que el Estado debe funcionar como una empresa y todos sus servicios deben ser competitivos. Toda actividad tiene que ser, por ley, organizada como una actividad rentable. Por ejemplo, la investigación en las universidades está organizada como una actividad que debe perseguir la rentabilidad económica: eso es el neoliberalismo y, una vez que penetra en el Estado y establece sus normas, cualquier gobierno es sometido a su dinámica. Eso es el neoliberalismo, si se puede establecer una —¿cómo decirlo? - una clasificación de los líderes políticos con respecto al neoliberalismo, analizando su discurso con respecto a esas normas que definen al neoliberalismo como modelo de civilización, hay algunos que son muy cercanos y otros que son incompatibles con eso.

Pero no creo que se pueda decir que el neoliberalismo es en sí mismo posfascista o fascista. Por definición, el neoliberalismo es totalitario porque una sociedad íntegramente neoliberal es una sociedad en la cual la democracia es totalmente evacuada en todos los sentidos, en la cual las libertades no existen más, en la cual todas las relaciones humanas son reificadas. En este sentido, el neoliberalismo es totalitario, pero no se puede decir que el neoliberalismo es totalitario porque sea una autopista hacia los campos de concentración, no es en este sentido.

\section{— Entonces, una posible alternativa que pueda enfrentar al neoliberalismo debería poder hacer un correcto diagnós- tico sobre su penetración social.}

- Sí, yo creo que sí. Hay que ser conscientes de que nos enfrentamos a un modelo de civilización y que está penetrando en todos los aspectos de las sociedades y de la vida. Es decir: el neoliberalismo implica que cada uno, que cada una, que cada ser humano conciba su vida como una competición, y tenga que organizar su vida como una empresa competitiva y exitosa. Eso penetra en el inconsciente colectivo y en nuestra manera de vivir. Por ejemplo, una parte de mi tiempo tengo que dedicarla a escribir reportes de actividades porque tengo que responder a la evaluación de un departamento universitario, de un programa académico, de un proyecto de investigación y de mis actividades. Tengo que dar cuenta de lo que hago. $Y$ todo eso es algo que, actualmente, pertenece a la normalidad, nuestra vida está organizada según esos criterios, entonces: mejor ser conscientes de eso. Quienes pertenecen a mi generación pueden darse cuenta de que, en otro tiempo, la universidad no funcionaba de esta manera. Pero las nuevas generaciones aceptaron de manera natural este funcionamiento de las instituciones y, esto, inevitablemente tiene consecuencias. Las llamadas "revoluciones de terciopelo" y las revoluciones árabes planteaban principios de igualdad en contra del neoliberalismo, eran anticapitalistas, y proponían el cambio radical 
en los criterios de funcionamiento. Pero su fragilidad, su carácter efímero, fue la expresión de la precariedad de la sociedad, de las sociedades en las cuales vivimos.

Por ello, el neoliberalismo es mucho más que un conjunto de políticas de gobierno, es una forma de civilización.

Ciudad de Buenos Aires, 14/11/2018. 


\section{Resumen}

Las presentes reflexiones son el resultado de una serie de conversaciones con Enzo Traverso que tuvieron lugar a mediados de noviembre, en la ciudad de Buenos Aires. Traverso es un historiador italiano doctorado en París que, actualmente, se desempeña como docente e investigador en Estados Unidos. Autor de importantes libros sobre historia europea contemporánea, Enzo Traverso ha escrito numerosas reflexiones sobre la práctica historiográfica y sobre la relación entre memoria, política e historia. En su última visita a la Argentina, dictó conferencias y seminarios en el marco del Encuentro Internacional Marx 200 años. En esta oportunidad, y a propósito de la publicación en español de sus dos últimos libros (Las nuevas caras de la derecha y Melancolía de izquierda. Marxismo, historia y memoria), aceptó debatir sobre las nuevas derechas latinoamericanas, los movimientos feministas, la situación de la izquierda a nivel mundial, y la naturaleza del neoliberalismo. Aquí presentamos y transcribimos el resultado de esas conversaciones.

\section{Palabras claves}

Nuevas derechas; Izquierdas; Feminismo; Neoliberalismo.

\section{Abstract}

The present reflections are the result of a series of conversations with Enzo Traverso that took place in mid-November, in the city of Buenos Aires. Traverso obtained his PhD degree at the École des Hautes Études en Sciences Sociales (Paris, France), who currently works as a professor and researcher in the United States. Author of important books on contemporary European history, Enzo Traverso has written numerous reflections on historiographical practice and on the relationship between memory, politics and history. During his last visit to Argentina, he gave lectures and seminars in the framework of the Marx 200 years International Encounter. On this occasion, and about the publication in Spanish of his last two books (The New Faces of the Right and Left Melancholy. Marxism, history and memory), he agreed to discuss the new Latin American rights, the feminist movements, the situation of the left worldwide, and the nature of neoliberalism. Here we present and transcribe the result of those conversations.

\section{Keywords}

New rights wing; Lefts; Feminisms; Neoliberalism. 